\title{
0 hospital psiquiátrico em diálogos atemporais
}

Bruno Ferrari Emerich ${ }^{(a)}$

Silvio Yasui ${ }^{(b)}$

"Por que a vida é muito simples: recebo de volta aquilo que dou"

Dizeres da cantina do Hospital Psiquiátrico Vera Cruz

Caro Silvio,

Cerca de três anos após participar de uma intervenção no Hospital Vera Cruz, localizado em Sorocaba (São Paulo), escrevo-Ihe estas narrativas. Quando da intervenção, essa região do estado de São Paulo era considerada o maior polo manicomial do país, contando com sete hospitais e cerca de dois mil e setecentos leitos.

Estive por três dias inteiros no interior do Vera Cruz participando de um Censo Psicossocial dos internados. Se não tenho o talento de Cláudio Edinger ${ }^{1}$ para transformar a realidade em fotografias vivas, espero ter sensibilidade narrativa para contar-lhe o que vivi por lá.

Acho importante ressaltar que o cenário descrito neste texto refere-se ao momento em que foi realizado o censo. Desde então, em Sorocaba, vários hospitais foram fechados, serviços foram abertos (como CAPS III, Serviços Residencias Terapêuticos etc.). Havia, naquele momento, uma efervescência de ações psicossociais e devolução da vida a vários usuários que, por anos, foram mortificados (que parece não mais ferver tanto...), sempre atravessada por poderes ocultos da contrarreforma que incidem ardilosamente sobre o projeto de fechamento dos hospitais. Sugiro que dê uma olhada mais próxima no contexto da saúde mental no município, para que tire suas próprias conclusões.

Opto por usar o recurso da narrativa, para tentar trazer alguma compreensão à humanidade histórica apresentada pela relação de exclusão da loucura, entendendo que a ação narrada está inserida numa práxis social ${ }^{2,3}$ e pode ajudar a ressignificar as relações e a trazer à tona a voz dos que ainda permanecem silenciados, sem poder narrar a própria história, por muitas vezes, nem nome terem.

Estava a ler seu texto a respeito da importância de aprendermos a perguntar sobre nossas práticas de ofertas de cuidados a sujeitos ditos loucos ${ }^{4}$. Chamou-me a atenção o fato de termos avançado em muitos pontos da mudança na lógica de cuidados, porém com continuidades e repetições perigosas.

(a) Departamento de Saúde Coletiva, Faculdade de Ciências Médicas, Universidade Estadual de Campinas. Rua Tessália Vieira de Camargo, 126, Cidade Universitária. Campinas, SP, Brasil. 13.083-887. brunoemerich@ yahoo.com.br (b) Departamento de Psicologia Evolutiva, Social e Escolar, Faculdade de Ciências e Letras, UNESP - Univ Estadual Paulista. Assis, SP, Brasil. syasui@assis.unesp.br 
Considerando a Reforma Psiquiátrica um processo composto por lutas de forças e poderes, é esperado que tenhamos avanços e retrocessos em seu curso. Ao tomarmos por base as dimensões jurídico-política, técnico-assistencial, sociocultural e epistemológica ${ }^{5,6}$, que compõem este processo, são notórios vários importantes avanços. Temos uma Política Pública de Saúde Mental que tem investido na criação de uma rede substitutiva de cuidados, recentemente apostando em maior integralidade de ações por meio das Redes de Atenção Psicossocial (RAPS), a partir dos princípios e diretrizes do Sistema Único de Saúde. Têm-se construído formas de organizar as ações, práticas e serviços de saúde mental considerando que o sujeito não pode ser reduzido à doença ${ }^{7}$, e que a interface entre clínica e gestão é fundamental para o redirecionamento do modelo de cuidados$^{8}$. Isto para citar alguns pontos, sem desconsiderar a importância de tantos outros, tantos que não caberiam neste texto.

Por outro lado, os sucessivos governos direcionam cada vez mais dinheiro público para o sistema privado de saúde ${ }^{9,10}$. No campo de cuidados aos usuários de álcool e outras drogas, após anos de omissão, por entender que tal esfera era da área da justiça, temos financiamento público da área da saúde para internação em Comunidades Terapêuticas, desconsiderando-se os caros pressupostos do vínculo, longitudinalidade de cuidado, integração da rede de cuidados e laicidade do Estado brasileiro. Isto para citar alguns pontos, sem desconsiderar a importância de tantos outros, que também não caberiam aqui.

O que justifica, então, a permanência de porões da loucura, como os que descreverei a você abaixo?

Certamente, práticas manicomiais podem prescindir dos muros hospitalocêntricos para existirem ${ }^{11}$, mas o modelo clássico de tratamento por Instituições Totais ${ }^{12}$ tira dos usuários o que mais os torna humanos: a singularidade e a liberdade. Por mais que se denominem "humanizados", ou tenham boa hotelaria.

Para tentar reassegurar o que me restou de identitário na breve estada no hospício, seguem excertos de um ainda vivo diário de campo. Se a experiência é o que nos toca, nos atravessa, nos acontece $^{13}$, o pensar e a construção destas narrativas procuram dar sentido ao que somos e ao que nos acontece: a nós, trabalhadores; a nós, corpo social; a nós, cidadãos; a nós, usuários do Sistema único de Saúde, no qual se inserem (sob gestão direta ou indireta) os Hospitais Psiquiátricos.

Abraços, e sigamos!

\section{Caro Bruno,}

Ler seu relato me deixou pasmo! Confesso que imaginava superada esta realidade que você vivenciou em plena segunda década do século XXI. Sua descrição me trouxe à memória os meus dias no Juquery, lá no início da década de 80 do século passado.

Resolvi tomar a sua descrição e a cada cena sua fazer um link para a minha cena.

\section{Dia 1}

Vera Cruz, 2012 - No corredor da ala de número que não me lembro, os interventores tinham por função conversar individualmente com cada interno, com o objetivo de confirmar se os prontuários do Hospital Psiquiátrico referiam-se aos internados, seus supostos donos. Se, por um lado, o prontuário é sempre visto em serviços de saúde como um instrumento burocrático, ou como uma obrigação instituída, pensei na subversão que seria usá-lo como estratégia instituinte: ver se os internados eram os que estavam no papel, fazer um Censo Psicossocial para examinar a existência de seus registros civis e avaliar graus mínimos de autonomia.

O dia quente ficava insuportável ao adentrar a ala. Era um corredor longo, dividido por grades, para que os internados não circulassem por todo o espaço. Nas laterais, ficavam os leitos e a sala de enfermagem.

Ao atravessar o portão de entrada, a partir da intervenção do carcereiro (ou enfermeiro?), fui abordado por alguns usuários.

Não entendi a lógica da divisão. Alguns conversaram comigo e, ao primeiro contato, estavam "mais normais" do que os que eu atendia no CAPS, ou discutia os casos em ações de matriciamento ${ }^{14}$ 
com as equipes das Unidades Básicas de Saúde. Cumprimentaram-me com aperto de mão, perguntaram-me o nome, quem eu era. Perguntaram qual era o meu time. Uma conversa trivial, a princípio.

Do final do corredor deste espaço onde todas as esferas da vida dos internados aconteciam sob a mesma autoridade ${ }^{12}$, vinham os gritos infindáveis. Somado ao calor, que grudava a roupa ao corpo, vinha o cheiro de urina. Lembrei-me de nunca mais reclamar sobre a sujeira de qualquer banheiro. Ao excesso de estímulos sensoriais, somava-se a necessidade de contato dos internados. Contato físico: seguravam-me enquanto passava, agarravam, pediam para tirá-los de lá. Os com menor grau de autonomia gritavam, urravam.

Ao aproximar-me da última grade, uma sensação inominável me tomava o corpo. O cheiro de urina era extremamente forte. Os gritos, insuportáveis. Um dos internados, surdo, gritava sem parar, em meio aos outros. Fiquei a pensar: parecia representar a surdez institucional, onde nenhum pedido é podido, onde nenhum desejo tem vez, onde a voz é ignorada, quando ainda existe. Perdi a noção de tempo cronológico.

Juquery, anos 80 - Apesar de estar situado em um amplo e belo jardim, os pavilhões onde ficavam os internados eram, via de regra, abafados e escuros. O cheiro forte de urina, fezes e desinfetante barato, deixava o ar ainda mais carregado. Talvez isso explicasse o fato dos pacientes gostarem tanto de ficar no pátio.

Minha primeira impressão ao entrar em um hospital psiquiátrico foi antes do Juquery. No ano de 1976. Ansioso, fui sendo conduzido por um auxiliar de enfermagem até o pátio. Para minha surpresa e decepção, não encontrei nenhum "Napoleão Bonaparte", ou algo que chegasse perto do que imaginava como sendo loucura. A impressão era de mendigos que se aproximavam para pedir cigarro, pedir para ir embora. Mas a conversa com muitos era, como você relatou, "normal", "cotidiana". Alguns apresentavam uns tiques e alguma dificuldade para falar, enrolando a língua, o que, descobri depois, tratava-se do efeito colateral da medicação.

A certa altura, depois que minha presença já não era mais novidade, fui percebendo algo que estranhei inicialmente, mas que no Juquery percebi ser uma constante: apesar de estar repleto de pacientes, havia um incômodo silêncio, interrompido uma hora ou outra por alguém que gritava para o nada, por murmúrios ou gemidos longos de angústia. Raros eram os pacientes que conversavam. Quase todos estavam ensimesmados, cabisbaixos. Minha percepção que fui construindo ao longo dos anos é a de que muitos desistiram da vida. Eram apenas corpos esperando a morte.

Corpos estirados no chão, sem movimento. O tempo se arrasta, quase se paralisa. Não fosse o ciclo do dia e da alimentação, nada alteraria o quadro. Certa vez, depois de muitas discussões e enfrentamentos, colocamos um espelho em uma enfermaria feminina. Quase todas as mulheres se espantavam ao verem em seu rosto as marcas do tempo: - "Nossa quem é essa velha aí no espelho? Não pode ser! Eu era tão jovem!" A imagem do espelho produziu naquelas mulheres um duro reencontro com a dimensão do tempo que a mortificante rotina do hospital destruiu.

Bruno, de modo diferente do que a canção de Cazuza nos dizia, o tempo no manicômio para.

Vera Cruz, 2012 - Na minha frente, uma grade branca, do chão ao teto. Do outro lado, cerca de trinta internados se espremiam contra ela, com as mãos por entre os vãos de ferro, procurando contato físico. Os funcionários estavam do lado protegido da grade, no intervalo em que ficavam os internados ditos "melhores".

Enquanto esperava o dono da chave abrir a grade para ir buscar o recenseado da vez, começou uma briga. Não sei o motivo, os barulhos se atravessavam, os gritos se sobrepunham. Duas pessoas começaram a socar-se, e caíram no chão. Os internados pareciam ter naturalizado a cena, tal qual naturalizavam as fezes e urina no canto da parede ao lado de onde as pessoas que brigavam caíram. Eu, do outro lado, fiquei momentaneamente sem estratégias para lidar com a situação. Senti-me um usuário em crise, como que sem estratégias para lidar com o inominável que de mim tomava conta, sem capacidade para nomear e elaborar o desconhecido que em mim se encarnava. Como num dado de realidade, ambos se levantaram e terminaram a briga por conta própria. Quando comecei a 
perceber-me integrado novamente, um interno nu tentou escalar a grade, e caiu em cima de vários outros. Vários no chão, entre nus e vestidos. O que sobraria de subjetividade ali? - perguntei-me.

Juquery, anos 80 - No Juquery, uma centena de mulheres caminha sob um sol escaldante. Urubus são cuidados como aves de estimação. Muitas estão nuas, e suas pernas sujas de sangue e sujeira. Uma disputa os restos de comida com um desses urubus. Neste lugar, duas pacientes morreram por insolação. Seus corpos só foram descobertos no início da noite, quando sentiram falta na contagem. Que subjetividade pode haver? O que houver será prova da resistência do humano a situações de extrema violência. Podemos chamá-los de "os sobreviventes".

Vera Cruz, 2012 - O carcereiro chegou, e, quando eu disse o nome de quem entrevistaria, ele orientou-me a tomar cuidado, pois havia perigo. Neste meio tempo, um outro funcionário tinha passado para o lado dos internados, para trazer a pessoa para avaliação. Sempre que uma pessoa cruzava as grades, este funcionário tinha de segurar vários outras, que tentavam de lá sair. Ou não, não sei se procuravam sair. A ação de sair nem parecia compor alguma rota na vida deles. O senso de existência parecia restrito à sobrevivência, não a itinerários ou percursos.

Chegou o internado, à minha frente. Enquanto caminhava até mim, vestia uma camiseta. Estendi-Ihe a mão, e ele a apertou cordialmente. Apresentei-me, dizendo meu nome e o que eu estava fazendo ali. Perguntei-lhe se ele gostaria de ir ao leito, onde poderíamos conversar com maior tranquilidade. Os gritos, o cheiro insuportável, o suor contínuo, a indefinição de contornos do corpo, me tomavam. Precisava de outro espaço para reconhecer-me, para então tentar reconhecer o outro, para poder escutar de fato um sujeito.

Não me preocupava com a denúncia de agressividade do interno, por parte do funcionário. Já tinha experiência de encontros com pessoas que, em dado momento, ficaram agressivas, e não me seria a primeira vez e nem o fim do mundo, se algo me acontecesse. Eu poderia apelar a meus colegas interventores, ou às teorias que estudei pela vida afora. Pensei, na hora, que ele há anos não tinha para quem pedir ajuda. O Estado estava a agredi-lo há tempos, sua identidade e singularidade foram mortificadas cotidianamente. Ele era o agredido.

Aceitou ir ao quarto. No quarto, olhando em seu olho, perguntei-lhe as condições de hospedagem, as ações cotidianas que conseguia exercer sozinho. Poucos minutos de conversa, ele disse que nada mais tinha a conversar, e voltou para a cela.

Enquanto ele voltava, eu procurava modos de interpretar o que eu vivera naqueles minutos. Não consegui articular Winnicott com Freud, nem Arouca com Amarante. Para me salvar, apareceu Álvaro de Campos: talvez um pouco de acidez para estapear-me, enquanto via o que produzimos sob o falso pretexto de proteção e suposto cuidado neste modelo de tratamento.

Olhei para o prontuário e a foto que lá constava correspondia à feição que vi, ao conversar com ele. Ele era ele mesmo. Pela foto, ele era ele mesmo. Mas o que dele sobrara, nesta experiência toda? Álvaro de Campos ${ }^{15}$ gritou-me, o suficiente para eu ouvi-lo em meio a tanto barulho: "sou quem falhei ser" (p. 338). Discordei dele, através de solilóquios. Ele, o interno, não era o que falhara ser, e sim nos esfregava na cara a nossa falha em considerá-lo sujeito, de desejos e direitos.

Obviamente, minha conversa mediúnica com uma das "personalidades múltiplas" de Fernando Pessoa não foi revelada a ninguém. Se assim fosse, certamente eu estaria lá até agora.

Juquery, anos 80 - Conheço uma paciente idosa, miúda, marcas do tempo em seu rosto de traços orientais. Sua idade era próxima aos 65 anos, embora aparentasse muito mais. Ela apenas falava japonês e tive dificuldade de compreender o que falava no meu pouco domínio da língua (coisas simples como bom dia, boa tarde, como vai). Olhando seu prontuário, descobri que havia sido internada no ano de 1938, aos 17 anos e nunca mais saiu. Mais de quarenta anos vivendo sem visitas e sem nenhum outro contato além do Juquery. Entre dezenas de páginas, havia poucas observações relevantes. Nenhuma referência à busca de contato com a família, a tentativas de localização. Nada. Apenas as prescrições de medicamentos e sessões de ECT. Um registro alguns anos após a sua entrada chamou a minha atenção: "paciente não fala português e limita-se a desenhar garranchos e linhas 
desconexas nas folhas de papel". Este gesto continuou ao longo dos anos. Na verdade era uma frase escrita em hiragana, que é um tipo de escrita japonesa um pouco mais sofisticada, o que revelava que, provavelmente, a paciente havia avançado nos seus estudos no Japão. Fiquei surpreso ao descobrir a tradução da frase repetidamente escrita: "socorro, por favor me ajude". Logo buscamos alguém que soubesse falar bem o japonês para conversar com ela. Em vão. Após os mais de quarenta anos, mesmo um falante não conseguia mais compreender o que ela dizia. E continua repetindo, mecanicamente o mesmo gesto, desenhando a mesma frase que ficou sem escuta por décadas. Ela faleceu um ano depois desta nossa tentativa.

Somos nós que falhamos ser.

\section{Dia 2}

Vera Cruz, 2012 - Num cômodo da antiga construção, ficavam guardados os mais de quatrocentos prontuários dos internados do asilo.

Como no contato presencial com os internados alguns dados psicossociais não foram conseguidos, e nas páginas iniciais do prontuário não constavam informações pertinentes, tornou-se necessária a leitura integral dos prontuários. Qualquer informação que trouxesse vida aos sujeitos poderia ser uma ponte para a passagem seguinte, para construção de uma rede comunitária de cuidados e de relações. Naquele momento, tratava-se de construção de ponte, antes da construção de redes: sujeitos que fossem transpostos do muro que os cerceava, dos olhares que os esqueciam, do silêncio que os anulava: um telefone ou nome de familiar registrado em alguma anotação, nome da cidade de origem, número de benefício previdenciário ou qualquer outra informação que ajudasse na construção de novas trilhas existenciais.

Ao abrir um prontuário, que a princípio era mais um, deparei-me com uma carta.

No momento, quase que automaticamente a peguei, como um arqueólogo que procura pistas ou vestígios de algo que já não mais existe. Quase de súbito, parei: o que me dava o direito de ler uma carta de uma pessoa que não conhecia? Logo coloquei-me no meu lugar, novamente: o que poderia parecer invasivo, se posto de forma descontextualizada, na verdade era uma ação que ajudaria no resgate ou emergência de um sujeito.

Era uma carta sem data, porém perceptivelmente escrita há muitos anos (talvez décadas), os mesmos que o prendiam naquele lugar. O envelope branco trazia tinta azul borrada, sem intensidade. Estava aberto, na lateral, com rasgo a prender o envelope na tira de papel que dele se separava. A carta cheirava a mofo, com o papel amarelado, e a tinta estava não menos enfraquecida do que a história registrada no envelope.

O internado escrevia à mãe, dizendo que estava com saudades, e que não queria ficar no hospital psiquiátrico. Pedia que ela fosse visitá-lo no final de semana e que levasse a comida preferida dele, que parecia marcar o encontro dominical da família: macarronada.

Após a leitura desta parte inicial, confesso não me lembrar mais do restante escrito naquele pedaço de papel. Lembro de tê-lo lido por completo, mas uma sensação fragmentadora tomou-me conta.

Comecei a pensar: se a carta estava no prontuário, é sinal que não fora entregue ao destinatário. Poderia ter sido por endereço errado, dado pela família, ou poderia ter sido esquecida pela própria instituição no prontuário, sem que fosse enviada. No envelope, não constava registro de devolução por endereço errado ou desconhecido.

Com as poucas evidências interpretativas que tinha naquele momento, fez-me mais sentido que a carta tivesse sido arquivada pelo próprio hospital. Se, em momentos anteriores a este da intervenção, já tinha visto moradores sem nome, sem registro civil, sem história; se soubera de mortes não explicadas, em número muito maior do que poderia esperar-se ${ }^{16}$, por que acreditar que a carta tivesse sido enviada?

Passei a imaginar o sujeito sem informações a respeito do envio da carta, e, provavelmente, sem informações da família (visto que, no prontuário, não havia registro de visita ou, mesmo, de nomes ou endereços de familiares), aguardando algum sinal, qualquer encontro. Tentei pensar no cotidiano de décadas de isolamento, onde a desesperança provavelmente tenha se transformado em conivência, onde o protagonismo certamente transformou-se em figuração, ou melhor, em ostracismo. 
Imaginei como seria levar esta carta ao sujeito, e ler para ele o conteúdo. O que faria ele? Reconhecer-se-ia? Indignar-se-ia? Ficaria indiferente, tal qual a instituição sempre fora com ele e com os outros mais de quatrocentos ali condenados à alta celestial? Certamente, seria uma importante mediação para um encontro clínico, porém, não era esta minha função, não haveria tempo para fazê-lo e, mais ainda, para construir sentidos disto junto a ele e continuar esta ação.

Angustiei-me. Indignei-me, como se me revelasse a ele, mesmo ausente.

Não se tratava de mais um prontuário.

Mais do que a carta que foi enviada e retornou sem ser aberta à sua origem, o que representaria o círculo de tudo que habita ou tangencia um hospício, ou de uma carta que não foi enviada, me tocava, naquele momento, a leitura que fez com que aquele sujeito voltasse a existir para alguém.

Certamente uma existência dilacerada, com formas de subjetivação a serem ressignificadas. Mas que parte da ideia de que a vida pressupõe movimento, e que a modulação de poder nas relações pode gerar resistência.

Gostaria de ter registrado em minha memória ou em alguma anotação o nome do interno. Gostaria de encontrá-lo algum dia, e acompanhá-lo nos itinerários daquela ou de outras cartas, na condição de usuário, não mais de interno. Provavelmente, com a perda de graus de autonomia e com a exponencialização dos efeitos gerados pela longa institucionalização, isto lhe seria interessante. A mim também.

Juquery, anos 80 - O abandono dos pacientes é também construído institucionalmente. Estar no manicômio já é sinal de que o esqueceram. Uma condenação a um isolamento perpétuo. Uma suspensão definitiva de seus mínimos direitos de cidadania. Seu relato da carta fez-me ecoar quantos pacientes me solicitaram escrever cartas para seus parentes os tirarem do hospício. Quantas cartas escrevi e quantas vezes tive de brigar para serem enviadas e acompanhar sistematicamente a resposta que quase nunca vinha.

Pinel, um dos criadores do hospital psiquiátrico, afirmava a importância do isolamento como um dos princípios fundamentais para o tratamento dos doentes mentais. Recomendava romper todos os laços e retirá-los do convívio social para melhor serem observados e tratados. Ainda hoje, em muitos lugares de "tratamento" a correspondência é vigiada e violada.

Que produção de subjetividade e que tipo de vida podem-se construir em um espaço que surge como espaço de isolamento e de restrição da liberdade? Como transformar uma instituição marcada secularmente por esta história?

\section{Dia 3}

Vera Cruz, 2012 - Nunca pensei que, aos 29 anos, voltaria a ficar desconfiado com o escuro. No anoitecer, no pátio do hospital psiquiátrico, deparei-me com esta sensação novamente.

Era o final dos trabalhos do terceiro dia da intervenção no hospício; intervenção esta judicialmente legitimada pelo Ministério Público e realizada por diversas instâncias do Estado, com a participação de pesquisadores e militantes de diversos locais do país.

Se a intervenção era diversa, o ambiente encontrado era massificado, como as descrições de Goffman ${ }^{12}$ cravaram.

Em três dias de intervenção, nos mais de quatrocentos leitos, ocorreu a morte de dois internados e transferência de vários usuários para hospital geral, por questões clínicas.

Fui responsável pela coordenação do trabalho na "ala das crianças". Ala das crianças porque os internados entraram quando crianças. Atualmente, os cerca de trinta moradores encontram-se infantilizados, mas não mais crianças, pois pareciam ter perdido o direito de sonhar.

Numa conversa com um deles, perguntei há quantos anos ele estava internado. "Há cem anos", ele responde. Não satisfeito, devolvi. "Nossa, mas então quantos anos você tem?". "Quatrocentos", foi a resposta. Morando num quarto há cerca de vinte anos, sem pertences pessoais ou visita de familiares, sendo o domingo igual à segunda ou à terça, tendo a noção de tempo a partir das alimentações diárias, do nascer e pôr do sol....sintoma psicótico ou institucional? 
Cheguei à conclusão de que o medo não era do escuro. Era do desconhecido que nos tornamos ao produzir tais condições na sociedade em que vivemos, no campo de trabalho em que atuamos. Se o olhar e escuta produzem subjetividade, como você tantas vezes me disse, qual seria produzida nesta lógica? Quais podem ser produzidas, com outros modos de cuidado?

Cerca de dez internados não tinham nome, nem documento qualquer, nem história no prontuário. Eram chamados por um nome escolhido por alguém (sabe-se lá quem os batizou institucionalmente), acompanhado pelo sobrenome indeterminado: Jorge Desconhecido, Carlos Anônimo.

O modo como cuidamos dos sujeitos, a clínica que construímos, as posições ético-políticas que escolhemos em ações e serviços nos formam, mas formam também quem atendemos. Não quero ser um Bruno Desconhecido, nem pactuar com ações no campo da saúde mental que tornem os outros Anônimos.

Juquery, anos 80 - Muitos dos pacientes que conheci tinham como nome no registro de seu prontuário: Fulano de Tal; Maria de Tal; José de Tal; Desconhecido 43, Desconhecido 41; Maria sem sobrenome; José sem sobrenome.

E muitos destes sabiam perfeitamente seu nome. Era comum apresentarem-se "José da Silva Sampaio, nascido em São Paulo, no ano de 1945. Meu Pai chama-se Raimundo Nonato da Silva Sampaio e minha mãe Maria da Silva Sampaio". E no prontuário o seu registro: Fulano de Tal. Mesmo afirmando e reafirmando seu nome e sua história, raramente o nome era modificado. Sua palavra pouco valia. O registro era mais importante do que a sua história e a narrativa de sua vida. A burocracia institucional era mais importante do que o encontro entre o paciente e o cuidador.

Vale aqui, diante de tantas lembranças e fatos revisitados e atualizados tristemente, relembrar Hannah Arendt.

O domínio de Ninguém é claramente o mais tirânico de todos, pois aí não há ninguém a quem se possa questionar para que responda pelo que está sendo feito. É este estado de coisas que torna impossíveis a localização da responsabilidade e a identificação do inimigo, que está entre as mais potentes causas da rebelde inquietude espraiada pelo mundo de hoje, da sua natureza caótica, bem como da sua perigosa tendência para escapar ao controle e agir desesperadamente. ${ }^{17}$ (p. 16)

\section{Dias que virão...}
Da minha aldeia vejo quanto da terra se pode ver no Universo... Por isso minha aldeia é tão grande como outra qualquer Porque eu sou do tamanho do que vejo E não do tamanho da minha altura.... Alberto Caeiro ${ }^{15}$ (p. 87)

Prezado Silvio,

A história da Reforma Psiquiátrica no Brasil ousa uma mudança paradigmática. De doença mental para saúde mental. De interno para usuário. De um único lugar de tratamento para o tratamento comunitário, ampliado, em rede. Da loucura do outro para a loucura como dimensão humana, entre nós, de todos nós.

Isto, como você bem viveu desde o Manifesto de Bauru, nunca foi nos dado facilmente. Foi sempre conquistado, disputado, tensionado.

Lembrei-me de um trecho de uma poesia do Álvaro de Campos $^{15}$ (em que ele fala das agruras da vida por meio do suicídio, veja só!), em que ele diz: "Se ousares, ousa!" (p. 357). Se ousamos no passado, havemos de continuar a ousar no presente e futuro. Ou será assim, ou nada será das mudanças que queremos.

Ousarmos no fortalecimento do que conquistamos. Ousarmos criticar nosso caminho, para eventuais mudanças de percurso. Ousarmos na recusa a repetições de práticas excludentes, que tanto queremos superar. Evitarmos os "museus de grandes novidades", como diria o poeta popular dos anos em que você esteve no Juquery. 
Afinal, o que queremos é que as pessoas possam ver mais coisas dentro de sua própria aldeia, como disse o Alberto Caeiro. Mas também esperamos que as pessoas possam, além de ver, experimentar, sentir, afetar-se, transformar-se. Nas aldeias ou lugares onde vivem, mas também em outras aldeias a serem descobertas. Aumentar o mundo, ser maior que a própria altura.

Isto não se faz trancado num hospital psiquiátrico.

É isso Bruno,

a vida é maior do que qualquer instituição e isso vale também para os CAPS. A pulsação desejante que emana das relações que estabelecemos deve ter o palco e o cenário da vida vivida em liberdade, que é o melhor modo de começar o cuidado.

\section{Colaboradores}

Os autores participaram, igualmente, de todas as etapas de elaboração do artigo.

\section{Referências}

1. Edinger C. Madness. England: Dewi Lewis Publishing; 1997.

2. Ricoeur P. Tempo e narrativa. Campinas: Papirus; 1997.

3. Onocko Campos R, Furtato JP. Narrativas: utilização na pesquisa qualitativa em saúde. Rev Saude Publica. 2008, 42(6):1090-6.

4. Yasui S. CAPS: aprendendo a perguntar. In: Lancetti A, organizador. Saúde Loucura. São Paulo: Hucitec; 1989. p. 47-59.

5. Amarante P. Saúde Mental e Atenção Psicossocial. Rio de Janeiro: Fiocruz; 2007.

6. Yasui S. Rupturas e encontros: desafios da reforma psiquiátrica brasileira. Rio de Janeiro: Fiocruz; 2010.

7. Campos GWS. Saúde Paidéia. São Paulo: Hucitec; 2003. p. 51-67.

8. Onocko Campos R. Psicanálise e Saúde Coletiva. São Paulo: Hucitec; 2013.

9. Bahia L. As contradições entre o SUS universal e as transferências de recursos públicos para os planos e seguros privados de saúde. Cienc Saude Colet. 2008; 13(5):1385-97.

10. Santos NR. SUS, política pública de Estado: seu desenvolvimento instituído e instituinte e a busca de saídas. Cienc Saude Colet. 2013; 18(1):273-80.

11. Emerich BF, Onocko Campos R, Passos E. Direitos na loucura: o que dizem usuários e gestores dos Centros de Atenção Psicossocial (CAPS). Interface (Botucatu). 2014; 18(51):685-96.

12. Goffman E. Manicômios, prisões e conventos. São Paulo: Perspectiva; 1974.

13. Bondia JL. Notas sobre a experiência e o saber de experiência. Rev Bras Educ. 2002; (19): 20-8. 
14. Campos GW, Domitti AC. Apoio matricial e equipe de referência: uma metodologia para gestão do trabalho interdisciplinar em saúde. Cad Saude Publica. 2007; 23(2):399-407.

15. Pessoa F. Antologia poética. Rio de Janeiro: Nova Aguilar; 2006.

16. Garcia MRV. A mortalidade nos manicômios da região de Sorocaba e a possibilidade da investigação de violações de direitos humanos no campo da saúde mental por meio do acesso aos bancos de dados públicos. Rev Psicol Polit. 2012; 12(23):105-20.

17. Arendt H. Sobre a violência. Rio de Janeiro: Relume-Dumará; 1999. 
O presente texto tem por objetivo apresentar um diálogo entre dois militantes da Reforma Psiquiátrica Brasileira que conversam sobre a imersão no cotidiano de hospitais psiquiátricos, mas a partir de vivências localizadas em diferentes tempos e em diferentes hospitais: Vera Cruz, em 2012, na cidade de Sorocaba; e Juquery, na década de 1980, em São Paulo. Bruno está em 2012, vivenciando um processo de intervenção em uma realidade manicomial que Silvio esperava já ter sido superada. Respeitadas as diferenças de lugares e das experiências por eles vividas, concluem que o modelo de tratamento proposto pelo hospital psiquiátrico apaga a fronteira do tempo e torna semelhantes as realidades que mortificam sujeitos e naturalizam práticas de segregação.

Palavras-chave: Hospitais psiquiátricos. Reforma Psiquiátrica Brasileira. Loucura. Desinstitucionalização.

\section{Psychiatric hospitals in timeless dialogues}

This paper aims to present a dialogue between two militants of the Brazilian Psychiatric Reform who talked about immersion in the daily life of psychiatric hospitals, but from experiences that were acquired in different hospitals and at different times: Vera Cruz, in the city of Sorocaba, in 2012; and Juquery, in São Paulo, during the 1980s. In 2012, Bruno experienced an intervention process within the reality of a psychiatric ward that Silvio had expected to have been surmounted. While respecting the differences in places and in experiences that they have been through, their conclusion is that the treatment model proposed by psychiatric hospitals has erased the boundaries of time and has led to similar realities that mortify subjects and naturalize segregation practices.

Keywords: Psychiatric hospitals. Brazilian Psychiatric Reform. Madness.

Deinstitutionalization.

\section{El hospital psiquiátrico en diálogos atemporales}

El presente texto tiene el objetivo de presentar un diálogo entre dos militantes de la Reforma Psiquiátrica Brasileña que conversan sobre la inmersión en el cotidiano de hospitales psiquiátricos, pero a partir de experiencias localizadas en diferentes tiempos y en diferentes hospitales: Vera Cruz, en 2012, en la ciudad de Sorocaba y Juquery, en la década de 1980, en São Paulo. Bruno está en 2012, viviendo un proceso de intervención en una realidad de manicomio que Silvio esperaba que ya se hubiera superado. Respetadas las diferencias de lugares y de las experiencias vividas por ellos, concluyen que el modelo de tratamiento propuesto por el hospital psiquiátrico borra la frontera del tiempo y hace semejantes las realidades que mortifican a los sujetos y naturalizan prácticas de segregación.

Palabras clave: Hospitales psiquiátricos. Reforma Psiquiátrica Brasileña. Locura. Desinstitucionalización. 